\title{
Co-integration Analysis of the Central and Eastern European Tourism Demand in Tunisia using Non-stationary Panel Data
}

\author{
By Chokri Ouerfelli* \\ Amel Abdellatif"
}

This paper aims to model the destination choice process of tourists from Central and Eastern Europe using non stationary panel data. If the unit root hypothesis is accepted, co-integration analysis is applied to estimate common long run demand relationships for these origin countries. The behavior of tourists from this part of the world is analyzed through estimated long run demand elasticities. The main finding of this study is that the existence of these relationships is expected given identical geopolitical and historical factors characterizing these countries. In addition to prices and income factors, the supply factor is introduced as an explanatory variable in the econometric model. The cointegrating relationships show that the large elasticity magnitude may be a reflection of tourism in Tunisia being regarded as a luxury by tourists. These results are corroborated by the estimated values of the short run demand elasticities obtained through the dynamic panel data model. They show also that only $1 \%$ of the increase in the tourist arrivals is due to tourist loyalty, which reflect the failure of the tourism policy in these markets to create and retain tourist loyalty to Tunisian services.

Keywords: Tourism demand, Non stationary panel data, Co-integration, Tourism policy..

\section{Introduction}

In a previous empirical work, the importance of the Western European market in Tunisian tourism was deeply highlighted. The factors that affect the destination choice process were identified and the European tourist behavior was analyzed (Ouerfelli 2008). This work concluded, among others, the importance of the supply factor to target more segments of tourist particularly throughout the year. This result is confirmed in a more recent work. It especially led to the conclusion that the financial performances of the tourism industry are not up to par compared to the important amount of investments allocated in this sector. Indeed, given the very competitive character of the tourism market, the professionals of this sector need to find other potential tourist markets that have not yet been explored. The Central and Eastern European market remains a real challenge for decision makers in Tunisia.

Since, the 1990's with the fall of the Berlin wall and the end of the Cold War, ex-communist countries are becoming more and more open to the rest of the world. These important changes have been taken into consideration by tourist professionals in Tunisia to target potential tourists from this part of the world.

${ }^{*}$ Professor, University of Sousse, Tunisia.

${ }^{\dagger}$ Graduate Student, University of Sousse, Tunisia. 
In fact, between 1992 and 2009, tourist arrivals from Eastern Europe and Russia rose from 48,000 to more than 480,000 tourists with an approximate average annual growth rate of $17 \%$. These countries accounted for about $10 \%$ of TArr from Europe and more than 14\% of the European Tourist bed-nights, but they provide the highest average length of stay (mainly Russia: 12.5 days; Poland: 10 days; Czech Republic: 10 days).

This important overall increase in tourist arrivals from this region can be detailed as follows: between 1991 and 1997 the average annual growth rate was of about $38.1 \%$, but grew only at an average rate of $7.5 \%$ per annum between 1997 and 2003 and 7.8\% per annum between 2003 and 2009. Then it is misleading to attribute this increase to any given tourism policy in Tunisia, however, the trend of this evolution reinforces the hypothesis that the efforts taken remain insufficient in responding to the expectations of this particular market.

A more in-depth analysis of potential tourist behaviors would be useful in many areas: first it provides researchers information on how these "new" tourists finalize their destination choice and identifies the main factors that explain this destination choice process. Secondly, used in an econometric model, these factors can then allow the professionals in this sector to influence this segment of the demand not sufficiently explored by examining the estimated demand elasticities. Thirdly, using potentially non-stationary panel data, this work allows verification for co-integration, which may outperform the statistical properties of estimated models and their forecasting performances. It provides an interesting alternative to systematical differentiation of time series. The co-integrating relationships express long run equilibrium demand and provide estimated demand elasticity in respect to economic variables used in this study (Income, Price and Supply).

After having described the evolution of the Eastern and Central European tourism market in the Tunisian economy during the study period, section 2 emphasizes the modeling strategy used in this work and its estimated methods consequences. The theoretical framework of units root tests strategies and cointegration analysis will be developed using panel data. The empirical results of the modeling procedure, the commentaries and their implications on tourism policy in Tunisia will be carefully discussed in the third section.

\section{The Central and the Eastern European Markets: A Real Challenge for the Tunisian Tourism Sector}

In this study, only the main origin countries from Eastern and Central Europe are considered: Hungary, Poland, Czech Republic, Slovakia, Croatia, Slovenia, Romania and Russia.

Considering the entire European market, available data covering between January and September 2010 indicated a significant fall in tourism activity in Tunisia due particularly to international financial crises. This fall affects not only tourism entry, but also the foreign currency receipts (-1.1\%). In fact, in 2009, the tourism industry generated $2536 \mathrm{MD}$ (millions of Tunisian dinar), instead of $2540 \mathrm{MD}$ during this period in 2010. However, it is misleading to attribute 
this bad financial performance only to the consequences of the financial crises; the European market fell $(0.7 \%)$ in 2008 as well. This fall was most probably due to an imbalance between supply and demand. This situation was apparently not the same for all the tourist origin countries, for example the Russian market actually increased about $46 \%$ during this period.

Table 1. Annual Average Means Increasing Rate (AAMIR) of Tourist Arrivals

\begin{tabular}{|l|c|c|c|c|c|c|}
\hline & \multicolumn{6}{|c|}{ Tourist arrivals: Increasing rate } \\
\hline O. Countries & $\mathbf{9 0 - 9 3}$ & $\mathbf{9 1 - 9 7}$ & $\mathbf{9 7 - ~ 2 0 0 3}$ & AAMIR & $\mathbf{2 0 0 3 - 0 9}$ & AAMIR \\
\hline Yugoslavia & 235 & 12 & -13.28 & -- & & \\
Czech & 623 & 402 & 65.05 & 8.71 & 2.97 & 0.49 \\
Republic & 114.5 & 561 & 94.0 & 11.68 & 72.42 & 9.50 \\
Russia & 493 & 321 & 191.4 & 21.43 & 222.02 & 21.52 \\
Poland & 87 & 274 & 42.8 & 6.12 & 64.70 & 8.67 \\
Romania & 489 & 255 & 227.1 & 36.44 & -45.71 & \\
Hungary & 352.5 & -12.6 & -79.2 & --- & 241.99 & 22.74 \\
Bulgaria & & & & & & \\
\hline
\end{tabular}

Table 1 clearly shows the significant and expected increase of the tourist arrivals from this area since 1990 as a consequence of the important geopolitical transformation of this part of the world. Between 1997 and 2003, this increase in tourist arrivals continued but at a lower intensity, which implies that tourist professionals in Tunisia have failed to respond to the demand requirements of these regions. The annual increasing rate of tourism activities is more and more synchronous.

\section{Modeling Strategy}

Many published studies on tourism demand show the importance of using econometric models to analyze tourist behaviors through the estimation of demand elasticities. These studies include, among others, Ouerfelli (2008, 2010), Dritsakis (2004), Song et al. (2003), Hiemstra and Wong (2002), Tan et al. (2002), Kulendran and Witt (2001), Smeral and Weber (2000), Song and Witt (2000), Kulendran and King (1997), Marley (1994), Martin and Witt (1989), Witt and Martin (1987).

Two major econometric approaches can be used: the non-causal (time series) and causal modeling approaches. The study based on non-causal modeling approaches "extrapolates the historic trends into the future without considering the underlining causes of the trends" (Song et al. 2003: 437) (e.g. Box-Jenkins 1976 ARIMA model and the exponential smoothing method). Indeed, the tourist demand model must consider the time path of the tourists' decision-making process (Song and Witt 2000: 28). When non-stationary variables are used, the co-integrating analyses may be a suitable alternative strategy to model integrated data. This can avoid the loss of information in the long run relationships between economic variables due to filtered time series. 
Considering the origin countries used in this study, it is likely that these consumers have the same behavior in regards to their countries' economic situations and the characteristics of tourist services supplied in Tunisia (dunes and sunny beaches) (see figure 1). Hence, it's expected that the macroeconomic tourism demand functions will be the same. However, a substantial heterogeneity can be explained by several factors:

- potential tourist characteristics, such as traveling habits, motivations, expectations, tastes, etc.;

- tourists' perceptions of Tunisia;

- other historical and non-economic factors that are difficult to measure.

It would be reasonable then to use panel data and to estimate a cross-section effect model (Green 2003).

In the following paragraph, the factors which may explain tourist destination choice will be presented. The dependent and the explanatory variables are then deduced.

\section{The Model Variables}

The identification of these factors is useful for two reasons. First, it provides researchers with information on how tourists finalize their destination choice. It can also allow forecasters to assess the manner (direction and magnitude) in which tourists would respond given any changes in the determining factors by examining the estimated demand elasticities. Secondly, these factors, used in econometric models, can help policy makers create economic strategies in order to influence the tourism demand (Witt and Witt 1995).

\section{The Dependent Variable}

The international tourism demand is often measured either in terms of the number of tourist arrivals, tourist bed-nights and/or in terms of tourist expenditure in the destination country.

In a recent study done on 107 papers about the quantification of international tourism demand, Norlida et al. (2010) found that the most cited dependent variables are tourist arrivals (59\%), tourist expenditure in the destination country (32\%), length of stay (6\%) and tourist bed-nights (3\%). Indeed, tourism in Tunisia is essentially sea-side mass tourism. The aim of decision-makers is then to have more tourists during all the seasons of the year. Therefore, it seems reasonable to quantify the tourist demand by the tourist arrivals (TArr).

\section{Determinants of Tourism Demand: The Explanatory Variables}

The tourist's destination decision process is the result of both individual characteristics (such as psycho-socioeconomic factors) and destination characteristics (such as historical and cultural heritage and natural wealth). The diversity of these factors illustrates the complexity of the identification process. To make 
this process feasible, only the factors which can be measured will be shown in this analysis.

A large consensus among researchers about tourist demand factors provide the use of income, relative prices, transport cost (Lim 1999) and the supply of tourist services (Johnson and Thomas 1992, Ouerfelli 2008, 2010) as explanatory variables in an econometric model. In fact, the relative price elasticity can provide useful suggestions for the formulation of pricing and competitive strategies. Income elasticity enables professionals to measure the impact (on tourism demand) of a change in revenue distribution in the origin countries (see Crouch 1992 and Song and Wong 2003). Finally, the supply induced demand elasticity enables decision makers in Tunisia to decide and manage the quality and the quantity of this variable according to tourist expectations ${ }^{1}$.

- The income is quantified by the gross domestic product per capita (GDP) (Ouerfelli 2008);

- The relative price is used to quantify the cost of tourism in Tunisia. This variable includes the tourists' living costs and the travel costs. The quantification of the first cost is based on the consumer price index (CPI) adjusted by the exchange rate (ER). The second is measured by the crude oil price;

- The supply factor must include an adequate infrastructure and, most importantly, hospitality. The accommodation capacity and touristic investments seem to be suitable proxies of the supply variable (see figure 2) (Ouerfelli 2008 and 2010, Choyakh 2008).

\section{The Sample}

Tourist data is obtained from an annual document "Le tourisme tunisien en chiffre" published by the Tunisian National Tourist Office (TNTO). However, the economic data is collected from the International Financial Statistics and the OCDE statistics. Here, data about Tourism arrivals (TArr), the income level (I) the relative price (P), the accommodation capacity (AC) and crude oil variable (CO) can be found from 1992 to 2009. The exchange rate is the quarterly average market rate of the local currency against the US dollar. Logarithmic transformations, which are used to express the multiplicative in the level of the variable, are applied and the transformed data is plotted below.

Note the two important dips in tourist activity were respectively during the $9 / 11$ period and in 2009. Surprisingly, as shown in these figures, globally the 9/11 events did not affect the tourist arrivals as expected. The significant negative impact of this phenomenon, appearing during the first quarter of 2002, was annihilated by the good performance of the tourism sector during the summer of the same year. "One of the advantages of using annual data is to avoid problems stemming from some conjectural shocks and/or seasonal effects" (Ouerfelli 2010).

${ }^{1}$ Johnson and Thomas (1992) highlighted the negative impacts of the hypothesis of an infinitely elastic tourist supply under the neoclassic assumption of the independence of supply and demand. 
Vol. 5, No. 2 Ouerfelli et al.: Co-integration Analysis of the Central and Eastern...

The second is due to the financial crises where its consequences still significantly affect almost all the tourist origin countries' economies. A dummy variable is introduced to capture the negative impact of this event.

Logarithms of the Dependent and the Explanatory Variables

Figure 1. The Logarithm of Tourist Entry (the dependent variable)

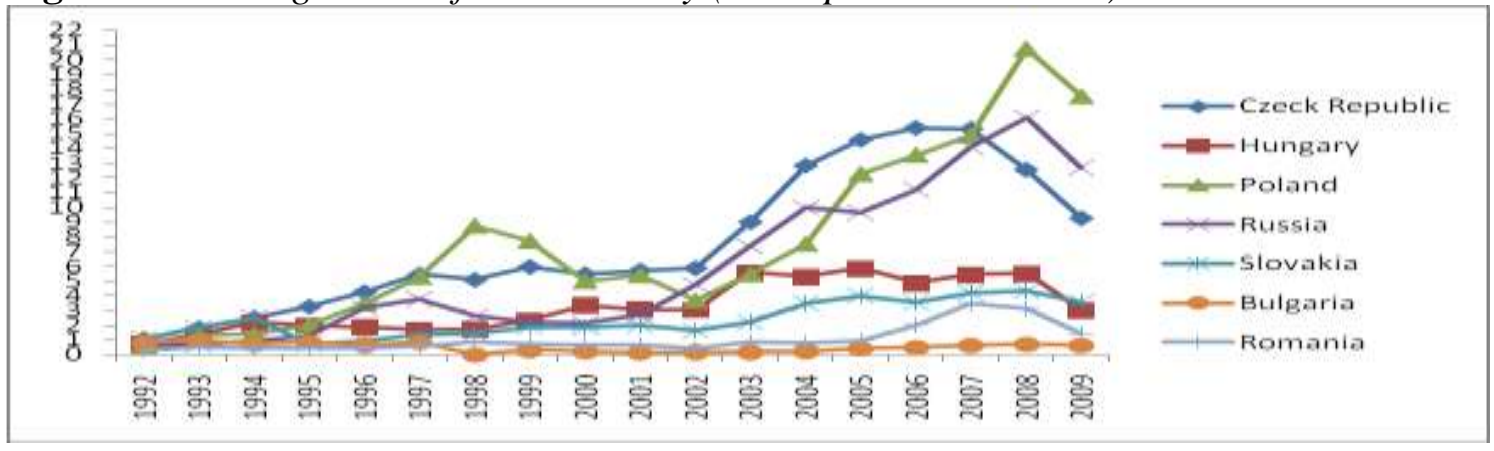

Figure 2. Logarithms of Explanatory Variables






\section{Co-integration Analysis}

In order to assess the relative explanatory power of the exogenous variables, it is suggested that insignificant variables be deleted until a parsimonious representation is obtained and the static panel model is implemented.

$$
\begin{aligned}
& \text { TArrit }_{i t}=\alpha_{i}+\beta_{1} \mathrm{GDP}_{i t}+\beta_{2} \mathrm{P}_{\mathrm{it}}+\beta_{3} \mathrm{CO}_{\mathrm{it}}+\beta_{4} \mathrm{AC}_{\mathrm{it}}+\varepsilon_{\mathrm{it}} \\
& \mathrm{i}=1, \ldots, 7 ; \mathrm{t}=1992, \ldots, 2009
\end{aligned}
$$

Using the STATA software, the following estimated results are obtained:

$$
\begin{aligned}
& \text { TArr }_{i t}=-0.62+4.75 \mathrm{GDP}_{\text {it }}-0.10 \mathrm{P}_{\mathrm{it}}-0.32 \mathrm{CO}_{\mathrm{it}}-0.39 \mathrm{AC}_{\mathrm{it}} \\
& (13.12)(0.49) \\
& \mathrm{R}^{2}=0.61, \mathrm{DW}=0.23
\end{aligned}
$$

The estimated values of DW statistic and the residuals figures show a strong residual autocorrelation probably due to the non-stationarity of the data (see appendix).

Indeed, an eventual non-stationarity of the TArr variable implies that using integrated variables will hold spurious results. However, first differenced variables used in panel data model provide only short run elasticities. Instead, long run behaviors can be analyzed through co-integration framework.

In this study non-differentiated variables are used. If the hypothesis of unit root is accepted, then co-integration analysis can be applied. It aims to statistically check for long run common demand relationships using integrated variables. We shall begin with testing for unit root. The Levin et al. unit-roots test procedure is applied to test for the existence of stochastic trends.

\section{Levin, Lin and Chu (2002) Unit-Root Test Results}

The non-stationarity of the data is probably due to the presence of unit roots; these series exhibit then a stochastic trend. The procedure, shown in this paragraph, was used to test for integrated time series in order to check for stationary demand relationships between these series.

To test for unit root, Levin et al. (2002) proposed a procedure based on the following auxiliary regressions

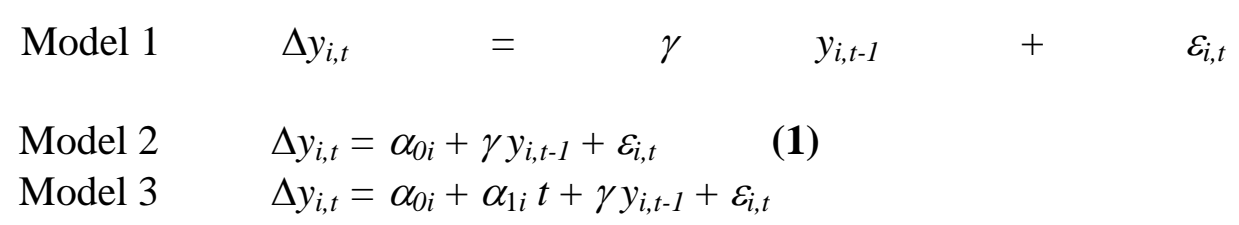


where $i=1, \ldots, \mathrm{N}$ and $\mathrm{t}=1, \ldots, \mathrm{T}$ and where $-2<\gamma \leq 0$ and $\varepsilon_{i, t}$ are a stationary ARMA process within cross sections $i . \Delta=(1-L)$ designates the first difference filter.

The error term $\varepsilon_{i t}$ is independently distributed through a stationary and inversible ARMA process: $\varepsilon_{i, t}=\sum_{j=1}^{\infty} \theta_{i j} \varepsilon_{i, t}+v_{i t}$

Pedroni's Co-Integration Test

When the series are an integrated process, difference filters can be used to achieve stationarity. The obtained stationary series can then be modeled with suitable econometric models. Given the loss of information due to differentiation, an interesting alternative consists of checking for stationary relationships between integrated series which may provide long run demand relationships.

To test for co-integration, Pedroni $(1999,2004)$ proposed a procedure based on the following auxiliary regression:

$\mathrm{y}_{\mathrm{it}}=\alpha_{\mathrm{i}}+\delta_{\mathrm{i}} \mathrm{t}+\beta^{\prime} \mathrm{X}_{\mathrm{it}}+\varepsilon_{\mathrm{it}}$
where $\beta=\left(\begin{array}{c}\beta_{1} \\ \beta_{2} \\ \beta_{\mathrm{a}}\end{array}\right), X_{\mathrm{it}}=\left(\begin{array}{c}\ln P_{\mathrm{it}} \\ \ln G D P_{\text {it }} \\ \ln C O_{\mathrm{it}} \\ \ln A C_{\text {it }}\end{array}\right)$

The main interest of this test is to check if the independent variables contribute to the explanation of the long run behaviors of tourist arrivals from Central and Eastern Europe in Tunisia.

\section{Empirical Results}

In this section, once a preliminary test for the order of integration is applied to the series, the estimation of long-run relationships is provided.

\section{$\underline{\text { Unit Root Tests }}$}

Using the Winrats6 software package, the Levin and Lin unit roots tests are applied to the logarithms of all the series to estimate the test equation (1) where the order of the auto-regressive augmentation is chosen in an experimental way.

The results are given in Table 2; they show that the hypothesis of root 1 is accepted at a 5\% level for all the series, which implies that they have nonstationary stochastic trends. 
Table 2. Unit Root Tests Results Using Winrats6

\begin{tabular}{|l|c|c|c|c|c|}
\cline { 2 - 6 } \multicolumn{1}{c|}{} & \multirow{2}{*}{ Model } & \multicolumn{2}{|c|}{ Without linear trend } & \multicolumn{2}{c|}{ with linear trend } \\
\cline { 2 - 6 } \multicolumn{1}{c|}{ LnGDP } & & $5 \%$ & $10 \%$ & $5 \%$ & $10 \%$ \\
\hline & $\mathrm{M} 1$ & $\mathrm{I}(1)$ & $\mathrm{I}(1)$ & $\mathrm{I}(1)$ & $\mathrm{I}(1)$ \\
\cline { 2 - 6 } & $\mathrm{M} 2$ & $\mathrm{I}(1)$ & $\mathrm{I}(1)$ & $\mathrm{I}(1)$ & $\mathrm{I}(1)$ \\
\cline { 2 - 6 } & $\mathrm{M} 3$ & $\mathrm{I}(1)$ & $\mathrm{I}(1)$ & $\mathrm{I}(1)$ & $\mathrm{I}(1)$ \\
\hline \multirow{3}{*}{$\operatorname{LnP}$} & $\mathrm{M} 1$ & $\mathrm{I}(0)$ & $\mathrm{I}(0)$ & $\mathrm{I}(0)$ & $\mathrm{I}(0)$ \\
\cline { 2 - 6 } & $\mathrm{M} 2$ & $\mathrm{I}(1)$ & $\mathrm{I}(1)$ & $\mathrm{I}(0)$ & $\mathrm{I}(0)$ \\
\cline { 2 - 6 } & $\mathrm{M} 3$ & $\mathrm{I}(1)$ & $\mathrm{I}(1)$ & $\mathrm{I}(1)$ & $\mathrm{I}(0)$ \\
\hline \multirow{3}{*}{$\operatorname{LnEnt}$} & $\mathrm{M} 1$ & $\mathrm{I}(1)$ & $\mathrm{I}(1)$ & $\mathrm{I}(0)$ & $\mathrm{I}(0)$ \\
\cline { 2 - 6 } & $\mathrm{M} 2$ & $\mathrm{I}(1)$ & $\mathrm{I}(1)$ & $\mathrm{I}(1)$ & $\mathrm{I}(1)$ \\
\cline { 2 - 6 } & $\mathrm{M} 3$ & $\mathrm{I}(1)$ & $\mathrm{I}(1)$ & $\mathrm{I}(1)$ & $\mathrm{I}(1)$ \\
\hline
\end{tabular}

I(1) designates that the series is integrated of order 1 .

\section{Long-run Co-integration}

The Pedroni's co-integration test procedure is applied using the software RATS 6.0 and results are given in table 3 .

Table 3. Co-integration Test Results

\begin{tabular}{|l|c|c|c|}
\hline \multirow{2}{*}{ Test } & \multirow{2}{*}{ Statistics } & \multicolumn{2}{|c|}{ Estimated values } \\
\cline { 2 - 4 } & & \multicolumn{2}{|c|}{ Without linear trend } \\
\hline \multirow{4}{*}{$\begin{array}{l}\text { The Pedroni test } \\
(1999,2004)\end{array}$} & Panel v-stat & -0.156 & 0.383 \\
\cline { 2 - 4 } & Panel rho stat & 1.260 & 0.251 \\
\cline { 2 - 4 } & Panel pp-stat & 0.262 & 0.368 \\
\cline { 2 - 4 } & Panel adf-stat & -1.720 & 0.015 \\
\cline { 2 - 4 } & Group rho-stat* & 2.720 & 0.030 \\
\cline { 2 - 4 } & Group pp-stat* & 0.136 & 0.398 \\
\cline { 2 - 4 } & Group adf-stat* & -2.920 & 0.0056 \\
\hline
\end{tabular}

The program «multi-pc3-Pedroni» used here is available on the site: www.estima.com.

*According to these statistics, the null hypothesis of non co integration is rejected at the $5 \%$ level.

The results show that the hypothesis of co-integration is accepted at a 5\% significance level and a probability value 0.9844 . The same procedure provides the estimated co-integrating relationship:

$$
\begin{array}{rrr}
\operatorname{TArr}_{i, \mathrm{t}}= & 0.46 \mathrm{DI}_{\mathrm{it}}-0.71 \mathrm{P}_{i, \mathrm{t}}-6.23 \mathrm{CO}_{i, \mathrm{t}}+0.23 \mathrm{AC}_{i, \mathrm{t}} \\
(2.43) & (-10.63) & (-7.50)
\end{array}
$$

This estimated demand relationship particularly provides the estimated values of long run demand elasticities with respect to economic variables. Note that these results reflect the same behavior in the long run for tourists from the origin countries in this study. They are also useful for suitable economic strategies of decision makers in Tunisia to target this demand segment. 
The income and the relative price demand elasticities suggest that holidays in Tunisia are regarded as luxury goods and also more increasingly as necessities in the long run. By contrast, the results highlight the importance of the transport cost measured by the crude oil price. In fact, this variable appears to be highly elastic. This result is expected given the geographical position of these origin countries in respect to Tunisia. Finally, the estimated value of the accommodation capacity's elasticity corroborates the supply induced demand hypothesis. However, this variable is not statistically significant at a 5\% level. Indeed, its low value can be attributed to the following explanations. Firstly, the accommodation capacity is only a part of the supply in Tunisia. Certain supply aspects have not been taken into consideration due to data unavailability, such as Saharan, cultural, health tourisms, etc. Secondly, this variable does not reflect the importance of the climatic factor and the sea side character of tourism in Tunisia.

\section{Dynamic Panel Model}

The estimation of a dynamic panel data model provides short-run elasticities of tourist demand with respect to the different explanatory variables. Long-run elasticities can be computed by dividing each of the coefficients by $(1-\beta)$. Considering the above unit root tests results, the first difference filter $(1-\mathrm{L})=\Delta$ is applied to achieve stationarity, the dynamic equation is given by

$\Delta y_{i t}=(\gamma+1) \Delta y_{i t-1}+\beta^{\prime} \Delta x_{i t}+\Delta \varepsilon_{i t} \quad t=1, \ldots, \mathrm{T}$ and $i=1, \ldots, n$

where $\alpha_{i} \in \mathrm{IR}$ is the cross-section effect, and $x_{i t}$ is a vector of explanatory variables. The innovations $\varepsilon_{i t}$ is the time error term.

The following model is estimated and results are given below.

$\Delta \operatorname{TArr}_{i, \mathrm{t}}=(\gamma+1) \Delta \mathrm{TArr}_{i, \mathrm{t}-1}+\beta_{1} \Delta \mathrm{P}_{i, \mathrm{t}-1}+\beta_{2} \Delta \mathrm{DI}_{i, \mathrm{t}}+\beta_{3} \Delta \mathrm{AC}_{i, \mathrm{t}}+\beta_{4} \Delta \mathrm{CO}_{i, \mathrm{t}}+\varepsilon_{i t}$

$i=1, \ldots, 7 ; \mathrm{t}=1992, \ldots, 2009$

$\varepsilon_{i t}$ is the time variant idiosyncratic error term.

Dummy, a dummy variable included to capture the negative effects of the 9/11 events, takes the value of 1 in the above mentioned year and 0 otherwise.

Note that the inclusion of the investment and the crude oil variables in the static model provides unexpected estimated results. They show a statistically non-significant coefficient at a $10 \%$ level. These results are probably due to both a specification error and/or a multi co-linearity problem. To avoid this problem, these variables are eliminated from the regression model.

The GMM technical is applied to estimate the unknown parameters (the second difference of the explanatory variables is introduced as instrumental variables in the estimated procedures). The estimated demand equation is then as followed: 
$\Delta \operatorname{TArr}_{i, \mathrm{t}}=-0.01 \operatorname{TArr}_{i, \mathrm{t}-1}+5.5 \Delta \mathrm{DI}_{i, \mathrm{t}}-0.10 \Delta \mathrm{P}_{i, \mathrm{t}}-0.009 \Delta \mathrm{CO}_{i, \mathrm{t}}+4.90 \Delta \mathrm{AC}_{i, \mathrm{t}}$

The coefficients are highly statistically significant at a $1 \%$ level and correspond in sign and magnitude to the economic theory. Empirical results show only $1 \%$ of the increase in tourist arrivals is due to tourist loyalty. This low value corroborates the preliminary conclusion which stipulates that the tourism policy in Tunisia aiming to target and increase tourist loyalty from these regions remains insufficient. An efficient strategy should include, among others, a heterogeneous and high-quality supply in order to respond to these tourists' exigencies.

Empirical results show the high level of the short-run income and price elasticities, which may reflect the luxury character of holidays in Tunisia. However, considering the long run demand elasticities, it can be concluded that tourism in Tunisia is regarded mainly as a luxury by tourists from these European regions, but also more and more as a necessity. The estimated value of the accommodation capacity elasticity corroborates the supply induced demand hypothesis, and significantly shows the importance of the supply factor in a suitable strategy targeting more tourists from this region. Note that in the long run, the impact of this variable is of low significance.

\section{Conclusion}

The tourism demand from Central and Eastern European markets was analyzed and modeled using non-stationary panel data framework. Unit root tests and co-integration analysis were applied to estimate long-run demand elasticities in respect to income, price and supply variables. The dynamic panel data model was also estimated. Short run demand elasticities were then generated and the tourism loyalty and the reputation effect were measured through the inclusion of the lagged dependent variable.

The modeling strategy used for the first time in this study, provided useful information and insight into many statistical and economical studies. On the statistical point of view, when non-stationary variables are used, co-integration analysis is an interesting alternative to model these variables without loss of information due to systematic differentiation. This procedure probably improves the model statistical performances through an increase in the degree of freedom.

On the economical point of view, interesting aspects of tourism activity are generated. The estimated long and short-run demand elasticities provide some useful insights on tourist characteristics and their expected behaviors useful for suitable strategies created by tourist professionals in Tunisia considering these merely explored markets. Empirical results show that tourism in Tunisia is regarded as a luxury by tourists from these European regions; however it is becoming more and more a necessity.

Furthermore, these results gave an empirical justification of the supply induced demand hypothesis. The supply factor was significant in the destination choice decision process. However, its low impact was attributed to the approximated character of the accommodation capacity. This variable reflected 
only a part of the supply in Tunisia, the holding capacity. Many supply aspects such as Saharan, cultural, health tourism etc., are not taken into consideration in this study due to data unavailability. Indeed, these various supply aspects are probably not sufficiently highlighted in holiday packages, which may explain the low value of the tourist loyalty degree where only $1 \%$ of tourist arrivals from this part of Europe return to Tunisia after their first experience. A suitable tourism policy in these markets consists of diversifying and promoting highquality services in order to lengthen the duration of stay and to create and retain tourist loyalty.

\section{References}

Box GEP, Jenkins GM (1976) Time Series Analysis, Forecasting and Control. San Francisco, CA: Holden Day.

Choyakh H (2008) A model of tourism demand for Tunisia: inclusion of the tourism investment variable. Tourism Economics 14(4): 819-838.

Crouch GI (1992) Effects of income and price on international tourism. Annals of Tourism Research 19: 643-664.

Dritsakis N (2004) Cointegration analysis of German and British tourism demand for Greece. Tourism Management 25: 111-119.

Green W (2003) Econometric Analysis ( $5^{\text {th }}$ ed). Upper Saddle River, New Jersey, USA: Prentice Hall, Pearson education Inc.

Hiemstra SJ, Wong KF (2002) Factors affecting demand for tourism in Hong Kong. Journal of Travel and Tourism Marketing 12(1-2): 43-62.

Johnson P, Thomas B (1992) Choice and Demand in Tourism. London: Mansell.

Kulendran N, King ML (1997) Forecasting international tourist flows using error correction and time series models. International Journal of Forecasting 13: 319327.

Kulendran N, Witt SF (2001) Cointegration versus least squares regression. Annals of Tourism Research 28: 291-311.

Levin A, Lin CF, Chu CJ (2002) Unit Root Tests in Panel Data: Asymptotic and Finite-Sample Properties. Journal of Econometrics 108: 1-24.

Lim C (1999) A meta-analysis review of international tourism demand. Journal of Travel Research 37: 237-284.

Marley C (1994) The use of CPI for tourism prices in demand modeling. Tourism Management 15(5): 342-346.

Martin C, Witt SF (1989) Forecasting tourism demand: a comparison of the accuracy of several quantitative methods. International Journal of Forecasting 5: 7-19.

Norlida Hanim, Osman RM, Hassen MA, Safar HM (2010) Malaysian tourism demand from the Middle East market: a preliminary analysis. International Journal of West Asian Studies (2): 37-52.

Ouerfelli C (2008) Co-integration analysis of quarterly European tourism demand in Tunisia. Tourism Management 29: 127-137.

Ouerfelli C (2010) Analysis of European tourism demand for Tunisia: a new approach. International Journal of Tourism Policy 3(3): 223 - 236.

Pedroni P (1999) Critical values for cointegrating tests in heterogeneous panels with multiple regressors. Oxford Bulletin of Economics and Statistics 61: 653-670. 
Pedroni P (2004) Panel Cointegration; Asymptotic and finite sample properties of pooled time series tests with an application to the purchasing power parity hypothesis. Econometric Theory 20: 597-62.

Smeral E, Weber A (2000) Forecasting international tourism trends to 2010. Annals of Tourism Research 27(4): 982-1006.

Song H Witt SF (2000) Tourism Demand Modelling and Forecasting. Modern Econometric Approaches, Pergamon, Oxford.

Song H, Witt SF, Jensen TC (2003) Tourism forecasting: accuracy of alternative econometric models. International Journal of Forecasting 19: 123-41.

Song H, Wong KF (2003) Tourism modeling: a time varying parameter approach. Journal of Travel Research 42(1): 57-64.

Tan YF, McCahon C, Miller J (2002) Modelling tourist flows to Indonesia and Malaysia. Journal of Travel and Tourism Marketing 12 (1-2): 63-84.

Witt SF, Martin CA (1987) Econometric models for forecasting international tourism demand. Journal of Travel Research 23-30.

Witt SF, Witt C (1995) Forecasting tourism demand: A review of empirical research. International Journal of Forecasting 11(3): 447-475. 
